\title{
Determinants of utilisation rates of preventive health services: evidence from Chile
}

\author{
Elena S. Rotarou ${ }^{1}$ and Dikaios Sakellariou ${ }^{2^{*}}$ (D)
}

\begin{abstract}
Background: Preventive health services play a vital role in population health. However, access to such services is not always equitably distributed. In this article, we examine the barriers affecting utilisation rates of preventive health services, using Chile as a case study.

Methods: We conducted a cross-sectional study analysing secondary data from 206,132 Chilean adults, taken from the 2015 National Socioeconomic Characterisation Survey of the Government of Chile. We carried out logistic regressions to explore the relationship between the dependent variable use of preventive services and various demographic and socioeconomic variables.

Results: Categories more likely to use preventive services were women (OR=1.16; $95 \% \mathrm{Cl}: 1.11-1.21)$ and inactive people $(\mathrm{OR}=1.41 ; 95 \% \mathrm{Cl}: 1.33-1.48)$. By contrast, single individuals $(\mathrm{OR}=0.85 ; 95 \% \mathrm{Cl}: 0.80-0.91)$ and those affiliated with the private healthcare provider ( $\mathrm{OR}=0.89 ; 95 \% \mathrm{Cl}: 0.81-0.96)$ had fewer odds of undertaking preventive exams.

Conclusions: The findings underline the necessity of better information campaigns on the availability and necessity of preventive health services, addressing health inequality in accessing health services, and tackling lifestyle-related health risks. This is particularly important in countries - such as Chile - characterised by high income inequality and low utilisation rates of preventive health services.
\end{abstract}

Keywords: Preventive health services, Healthcare, Public health provider, Private health provider, Chile, Health inequality

\section{Background}

Global demographic, epidemiological, and socioeconomic changes - such as ageing, urbanisation, globalisation, and reductions in morbidity and mortality rates - have resulted in the increase in the prevalence of chronic diseases, and therefore, have underlined the need for effective strategies that will improve global health [1]. As a result, preventive health services have been introduced in many countries, since studies have shown that provision of such services can lead to health management in the early stage of diseases,

\footnotetext{
* Correspondence: sakellarioud@cardiff.ac.uk

${ }^{2}$ Cardiff University, School of Healthcare Sciences, Eastgate House, Newport

Road 35-43, Cardiff CF24 OAB, UK

Full list of author information is available at the end of the article
}

and that prevention can contribute to reducing the subsequent total demand for medical care [2].

In this article, we investigate the utilisation rates of preventive health services for Chilean adults (people of 15 years of age and over) and the various demographic, socioeconomic, and health-related factors influencing such rates. We focus particularly on differences in utilisation rates on the basis of affiliation with the public or private health provider. The importance of this study lies on the fact that Chile, as many other developed countries, has been experiencing an ageing of its population: the over-60 group - currently $11.1 \%$ of the population is expected to reach $13 \%$ by 2020 , underlining the increasing need for preventive services, as population becomes more likely to suffer from chronic and age-related diseases [3]. Despite the growing importance

(C) The Author(s). 2018 Open Access This article is distributed under the terms of the Creative Commons Attribution 4.0 International License (http://creativecommons.org/licenses/by/4.0/), which permits unrestricted use, distribution, and 
of preventive services, there are currently very few studies that have investigated preventive health services in Chile (for instance, Baechler, Barra and Soto, on preventive medicine index for the region of Maule; Sakellariou and Rotarou, on utilisation of cancer screening services by disabled women) $[4,5]$.

Unlike many international studies that have used specific subpopulations and health surveys to investigate utilisation of preventive health services and the factors affecting such rates (for example, Schülein et al., on participation in preventive health check-ups of German women; Yen et al., on use of preventive services among adults with intellectual disabilities in Taiwan) $[6,7]$, in this study we use cross-sectional data from over 200,000 Chilean adults from the general population, available from the National Socioeconomic Characterisation Survey of the Government of Chile.

This article contributes to existing literature by investigating the influence of health care provider on the utilisation rates of preventive services. In the context of highly unequal access to health care services, and neoliberal practices in the Chilean health system [8-10], such an investigation is very important, since it can guide policy makers in the design, implementation, and monitoring of strategies, which will address not only the availability of preventive health services but also possible obstacles in the effective access and utilisation of such services. Overall, this study addresses a gap in existing literature, both in terms of contribution to general knowledge on utilisation rates and possible barriers affecting preventive health services, but also in terms of knowledge about access and utilisation of preventive exams in Chile, a country characterised by high income inequality and stratification of its health care services.

We first give a brief presentation of the health system and preventive health services in Chile, before moving on to the methodology and study results, which we critically discuss in tandem with relevant literature.

\section{Health system and preventive health services in Chile}

The health coverage in Chile is universal, that is, all citizens are entitled to access and utilisation of health care services. The public health care provider (Fondo Nacional de Salud, FONASA) is divided into four segments (A, B, C, and D), according to individual or family income; very poor people or people without any income belong to segment $\mathrm{A}$ and receive treatment free of charge. In 2016, most Chileans (74.4\%) were affiliated with FONASA, while $18.7 \%$ of the population were affiliated with one of the private health care providers (Instituciones de Salud Previsional, ISAPREs); the remaining population either paid out-of-pocket or was affiliated with the health provider of the Armed Forces [11].

The separation of the health system in Chile into public and private providers - which took place during the late 1970s and early 1980s - led to the creation of health inequalities through the stratification of access and utilisation of health care services $[8,10,12]$. Thus, people from higher socioeconomic classes are usually affiliated with an ISAPRE, and enjoy better-quality health care services and timely attention, while people from lower socioeconomic classes access FONASA, which is usually characterised by much longer waiting times and poorer infrastructure. The contract premium for the ISAPREs is determined by age, sex, and risk factor, a fact that often excludes the elderly and women of reproductive age [12]. For example, in 2015 only $11.7 \%$ of total ISAPRE affiliates were people over 60 years of age, and only about $35 \%$ were women [13]. A recent study by the Superintendence of Health revealed that a 35 -year-old woman can pay $66 \%$ more on average for her ISAPRE plan than a 35-year-old man [14].

Concerning preventive health services, the Preventive Medical Examination (PME) was established in Chile as a public health policy, and was defined by the Superintendence of Health as a periodic, voluntary, and free health evaluation [15]. All individuals affiliated with either the public health care provider (FONASA) or the private providers (ISAPREs) are entitled to use preventive exams free of charge themselves and their family, depending on their perceived health risk and age [16]. This PME is a periodic and voluntary health monitoring and evaluation plan that forms part of the Explicit Health Guarantees for Chileans benefits package (Acceso Universal a Garantías Explícitas en Salud- Garantías Explícitas en Salud, AUGE-GES). The AUGE-GES plan establishes explicit guarantees for people in a group of eighty prioritised pathologies (as of July 2017), independent of their ability to pay for health services and treatment.

The available preventive health services for adults (people aged 15 and older) in Chile include the following: screening and early detection of alcohol misuse (identification of risk behaviours and prevention options), identification of smoking problem (through medical history and/ or test of Fagerström to check level of smoking addiction), identification and treatment of overweight and obesity, as well as various tests to identify, measure and/or assess arterial hypertension, diabetes mellitus, syphilis, and tuberculosis. Women aged 25-64 are entitled to Papanicolaou cervical smear test to screen for cervical cancer, and women aged 50-69 to a mammography for breast cancer. Adults of 40 years of age and older can undertake dyslipidaemia controls, and people of 65 years of age and older can undergo various screening tests to assess their 
functional independence [17]. These preventive health checks are available free of charge only under the following circumstances: a) if individuals are affiliated with FONASA, they can ask for the corresponding health services at the health facility where they are registered; and b) if individuals are affiliated with an ISAPRE, they can have preventive services only at the health facilities and with the doctors with which their ISAPRE has a plan [16].

In 2015, there were 1,605,219 Chilean adults (about $11.2 \%$ of the total population of 15 years of age and older) that used preventive services, out of which $43.4 \%$ were male and $56.6 \%$ female [18]. This number reflects only preventive health services performed in the public health system. Regarding preventive health checks in the private system, the information is quite scarce. Preventive checks in private hospitals or clinics in the capital, Santiago, have increased in the last five years by $30 \%$; between 1500 and 6500 people undergo such exams every year at each private hospital, with the majority being men with an average age of 50 [19]. Taking into account this information, a rough estimate of the percentage of Chileans adults that use preventive services every year in the country would put it at about $13-14 \%$ of the total adult population (about 14 million in 2015).

\section{Methods}

\section{Study aims}

The main aim of the study was to examine the utilisation rates of preventive health services for Chilean adults in 2015, and the demographic, socioeconomic, and health-related factors influencing such utilisation. We also explored whether affiliation with the public or private health care provider influenced the utilisation rates of preventive services.

\section{Survey and methods}

The study was based on a secondary analysis of cross-sectional data available from the 2015 National Socioeconomic Characterisation Survey (Encuesta Nacional de Caracterización Socioeconómica - CASEN). CASEN is a survey conducted by the Ministry of Social Development of the Government of Chile every two to three years, since 1990. It is the main socioeconomic measurement instrument for the design and the evaluation of existing social policies in the country [20]. Its aim is the estimation of the magnitude of poverty and income distribution, the identification of the needs of the population, and the evaluation of the gaps that separate the different social segments and geographical areas. In order to achieve these goals, the survey is comprised of seven modules: Residents Registry, Education, Employment, Income, Health, Residents, and Housing [21].

The CASEN survey allows for up-to-date diagnoses on the situation of disadvantaged groups that are social policy priorities, such as children and adolescents, old people, indigenous people, and people with disabilities. It also offers information on a variety of other relevant social issues, such as access to information and communications technologies, and social participation; since 2015, it provides information on sexual diversity, the environment, and networks available to households [20].

The units of analysis (households and people) are selected in a probabilistic, stratified, and multistage manner, with the sample being representative at country level, geographical area (urban and rural), regional level (fifteen country regions), and municipal level (324 municipalities). The CASEN survey is a valid and reliable measure of reference, since the information provided there is consistent with that provided by other data sources, such as population censuses [22].

The 2015 CASEN survey covered 83,887 households, and a total of 266,968 people. Personal interviews were employed - lasting, on average, $47 \mathrm{~min}$ for a household of four people - from November 2nd 2015 until January 31st 2016. An interviewer with a questionnaire on paper interviewed the head of the household or a member of the household older than 18 years of age. No personal information, such as ID number or names, was requested during the interview. The microdata were fully anonymised and in the public domain (accessible from http://observatorio.ministeriodesarrollosocial.gob.cl/ casen/casen_2015.php), and therefore no ethical approval was required by the Universidad de Chile.

Logistic regressions were used to investigate the demographic, socioeconomic, and health-related factors that affected the utilisation rates of preventive health services of Chilean adults. Estimated probabilities of using preventive services, depending on health provider affiliation, were also calculated. We used STATA/MP version 14.2 for all calculations.

\section{Data and variables}

The sample size of the study included 206,132 observations (people younger than 15 years of age were excluded). People were asked whether they had undergone any health controls (with a subsequent list of various health checks). When people answered 'yes' to having used preventive health services, this answer was left as 'yes'; when people answered that they had not done any health exams or they had done other type of exams (for example, dental exams or controls of chronic illnesses), this answer was left as 'no'. As a result, the dependent variable 'use of preventive services' is a binary variable with answers 'no' and 'yes'.

The demographic, socioeconomic, and health-related variables that were used as controls in the study included the following: a) sex: man / woman; b) geographical location: urban / rural; c) age: years (people 15 years 
of age and older); d) civil status: married / living with someone or in a relationship / separated, divorced or annulled / widowed / single; e) indigeneity: not indigenous / indigenous (includes people from nine state-recognised indigenous groups); f) nationality: Chilean (Chilean or with double nationality, one of them being Chilean) / foreigner; g) health self-assessment: scores $1-2=$ 'bad' / scores 3-5= 'neither good nor bad' / scores 6 $-7=$ 'good'; h) health provider: FONASA (public) / Armed forces / ISAPRE (private) / out-of-pocket; i) disability: no disability / with disability; j) equalised income (log): household income divided by square root of household size (square root equivalence scale); k) education: years of schooling; and l) employment: employed / unemployed / inactive.

\section{Results}

\section{Descriptive statistics}

Table 1 summarises the characteristics of the study sample, revealing that more women than men use preventive health services (61\% vs. $39 \%)$, in agreement with relevant literature $[23,24]$. The average age of people using preventive services in our sample is 67 , with most of them (47\%) being married. More people that use preventive services are affiliated with FONASA (89\%) and fewer are affiliated with an ISAPRE (7.4\%), compared to people not using such services (82 and 12.4\%, correspondingly). As expected, a higher percentage (59\%) of people not using preventive health services assess their health as 'good', while only $37 \%$ of people using such services do so; this may be related to the higher percentage of people using preventive services that have some kind of disability. Concerning socioeconomic status, more people not using preventive services are employed, earning a slightly higher income, and having more years of education, compared to people who do use such services.

Figure 1 shows the percentage of Chilean adults that underwent preventive services during the period 20002015. It should be noted that in the pre-2011 CASEN surveys, the general question on health controls and on preventive health services was slightly different: this can be reflected especially in the low percentage of people answering that they have used preventive services for the years 2000 and 2003.

According to the 2015 data, 5.5\% of Chilean adults used preventive health services, the highest percentage since the year 2000. The differences between years are statistically significant with $p<0.0001$, with the exception of 2009$2011(p=0.274)$. Concerning the vast majority of preventive health services for 2015, these were performed in public hospitals or public health centres; less than $9 \%$ of preventive services were performed in private medical centres. Regarding payment, the vast majority of people who used preventive services did not pay for them, mostly because they were affiliated with the public health provider.

\section{Logistic regressions}

Logistic regressions were employed in order to investigate the impact of various demographic, socioeconomic, and health-related factors on utilisation of preventive health services of Chilean adults. The mean variance inflation factor for all variables was 1.63 , indicating that there were no collinearity issues. The results of the logistic regressions are presented in Table 2. Model (1) shows odds ratios adjusted for demographic variables, Model (2) introduces socioeconomic variables, while Model (3) adds health-related variables (fully-adjusted odds ratios, all the variables of Table 1 included). A higher Mac Fadden $R^{2}$, and lower deviance, and AIC and BIC values, show that Model (3) provides a better fit than Models (1) and (2).

The results show that there is a gender difference, with women having 1.2 times (CI 95\%: 1.11-1.21) higher odds of using preventive services than men. People living in rural areas had 1.1 times (CI 95\%: .86-.95) fewer odds of undertaking preventive exams than people living in urban areas. Older people had higher odds of undergoing preventive services: one extra year increased the odds by 1.07 (CI 95\%: 1.06-1.07). Concerning civil status, being married was the status associated with a higher probability of using preventive services, while single people had the lowest probability of doing so (OR: .85, CI 95\%: .80-.91).

Furthermore, people with higher incomes had slightly higher odds of undertaking preventive exams than poorer people (OR: 1.13, CI 95\%: 1.09-1.17). Regarding employment, people that were inactive had 1.4 times (CI 95\%: 1.33-1.48) higher odds of undergoing preventive services. People with a good or an average self-assessed health score had 1.1 times (CI 95\%: 1.06-1.22) to 1.2 times (CI 95\%: 1.11-1.26) higher odds of undertaking preventive health checks than people who graded their health as 'bad'. People affiliated with an ISAPRE had 1.1 times (CI 95\%: .81-.96) fewer odds of undergoing preventive checks; people paying out-of-pocket had 2.4 times (CI 95\%: .33-.51) fewer odds of doing so, compared with people affiliated with FONASA.

More years of education did not have an impact on utilisation of preventive services; while statistically significant, the ratio approached 1 (OR: .99, CI 95\%: .98-.99), indicating no relationship. There was no statistically significant relationship between the remaining variables (that is, 'indigeneity', 'nationality', and 'disability') and utilisation rates of preventive health services.

Figure 2 presents the estimated probabilities for utilisation of preventive health services when the predictor variable is health provider, while holding the other predictor variables at their mean.

As it can be observed in Fig. 2, Chilean adults affiliated with FONASA had a higher probability of using preventive health services, followed by people affiliated with the Armed Forces' health care provider, and people affiliated 
Table 1 Demographic, socioeconomic, and health-related characteristics of the sample

\begin{tabular}{|c|c|c|c|}
\hline \multirow[t]{2}{*}{ Parameter } & & \multicolumn{2}{|l|}{$\begin{array}{l}2015 \\
(n=206,132)\end{array}$} \\
\hline & & No preventive services $(n, \%)$ & Preventive services $(n, \%)$ \\
\hline \multirow[t]{4}{*}{ Sex } & Male & $91,771(47.1 \%)$ & 4415 (38.9\%) \\
\hline & Female & $103,021(52.9 \%)$ & $6925(61.1 \%)$ \\
\hline & Chi-square test $p$-value & $p<0.0001$ & \\
\hline & Cramer's V & 0.037 & \\
\hline \multirow[t]{4}{*}{ Zone } & Urban & $151,961(78.0 \%)$ & $8746(77.1 \%)$ \\
\hline & Rural & $42,831(22.0 \%)$ & $2594(22.9 \%)$ \\
\hline & Chi-square test $p$-value & $p=0.027$ & \\
\hline & Cramer's V & 0.005 & \\
\hline \multirow[t]{5}{*}{ Age (mean, std. dev.) } & & $42.9(18.5)$ & $67.0(15.9)$ \\
\hline & t-test $p$-value & $p<0.0001$ & \\
\hline & Point biserial correlation & -.286 & \\
\hline & Married & $67,871(34.8)$ & $5319(46.9 \%)$ \\
\hline & Living with or in a relationship & $31,351(16.1 \%)$ & $921(8.1 \%)$ \\
\hline \multirow[t]{5}{*}{ Civil status } & Separated, divorced, annulled & $13,043(6.7 \%)$ & $905(8.0 \%)$ \\
\hline & Widowed & $9958(5.1 \%)$ & $2648(23.4 \%)$ \\
\hline & Single & $72,569(37.3 \%)$ & $1547(13.6 \%)$ \\
\hline & Chi-square test $p$-value & $p<0.0001$ & \\
\hline & Cramer's V & 0.202 & \\
\hline \multirow[t]{4}{*}{ Nationality } & Chilean & $191,779(98.5 \%)$ & $11,263(99.3 \%)$ \\
\hline & Foreigner & $3013(1.6 \%)$ & $77(0.7 \%)$ \\
\hline & Chi-square test $p$-value & $p<0.0001$ & \\
\hline & Cramer's V & -0.016 & \\
\hline \multirow[t]{4}{*}{ Indigeneity } & Not indigenous & $173,670(89.2 \%)$ & $10,356(91.3 \%)$ \\
\hline & Indigenous & $21,122(10.8 \%)$ & $984(8.7 \%)$ \\
\hline & Chi-square test $p$-value & $p<0.0001$ & \\
\hline & Cramer's V & -0.016 & \\
\hline \multirow[t]{6}{*}{ Health system } & FONASA & $159,586(81.9 \%)$ & $10,092(89.0 \%)$ \\
\hline & Armed forces & $4190(2.2 \%)$ & $325(2.9 \%)$ \\
\hline & ISAPRE & $24,210(12.4 \%)$ & $833(7.4 \%)$ \\
\hline & Out-of-pocket & $6806(3.5 \%)$ & $90(0.8 \%)$ \\
\hline & Chi-square test $p$-value & $p<0.0001$ & \\
\hline & Cramer's V & 0.052 & \\
\hline \multirow[t]{5}{*}{ Health score } & Bad & $13,036(6.7 \%)$ & $1487(13.1 \%)$ \\
\hline & Average & $67,685(34.8 \%)$ & $5632(50.0 \%)$ \\
\hline & Good & $114,071(58.6 \%)$ & $4221(37.2 \%)$ \\
\hline & Chi-square test $p$-value & $p<0.0001$ & \\
\hline & Cramer's V & 0.102 & \\
\hline \multirow[t]{4}{*}{ Disability } & No disability & $175,756(90.2 \%)$ & $8434(74.4 \%)$ \\
\hline & With disability & $19,036(9.8 \%)$ & $2906(25.6 \%)$ \\
\hline & Chi-square test $p$-value & $p<0.0001$ & \\
\hline & Cramer's V & 0.117 & \\
\hline Employment & Employed & $103,565(53.2 \%)$ & $3176(28.0 \%)$ \\
\hline
\end{tabular}


Table 1 Demographic, socioeconomic, and health-related characteristics of the sample (Continued)

\begin{tabular}{llll}
\hline Parameter & & $\begin{array}{l}2015 \\
(n=206,132)\end{array}$ & Preventive services (n,\%) \\
\cline { 2 - 3 } & & No preventive services (n, \%) & $156(1.4 \%)$ \\
& Unemployed & $8423(4.3 \%)$ & $8008(70.6 \%)$ \\
& Inactive & $82,804(42.5 \%)$ & $p<0.0001$ \\
Equalised income ${ }^{a}$ (mean, std. dev.) & t-test $p$-value & 0.130 & $509,400(549,153)$ \\
& Cramer's V & $528,348(671,874)$ & $7.8(4.9)$ \\
Education, (mean, std. dev.) & t-test $p$-value & $p=0.003$ & .006 \\
& Point biserial correlation & $10.6(4.2)$ & $p<0.0001$ \\
\hline
\end{tabular}

${ }^{a}$ Chilean pesos (1 USD $=659$ Chilean pesos, average July 2017)

with an ISAPRE. Chileans paying out-of-pocket had the lowest probability of using preventive health services. All predicted probabilities were significantly different from zero $(p<0.0001)$.

\section{Discussion}

This study investigated the utilisation rates of preventive health services for Chilean adults for 2015. It also looked at differences in utilisation rates due to affiliation with the public or private health care provider. Confirming the study's hypothesis, women were more likely to undergo preventive checks than men. This result agrees with previous studies [23, 25-28]. There are also a few studies that have shown no sex-specific difference in relation to preventive health services [24].

The findings also showed that older people had slightly higher odds of using preventive services than younger people. Research on age and use of preventive health services is quite diverse: some have shown an inverted U-turn relationship between age and preventive services
[24], others a linear relationship with regards certain preventive checks, such as blood pressure checks [25], other studies have shown country differences [29, 30], while others have shown no significant age differences in utilisation rates of preventive services [31].

Concerning civil status, being married was associated with a higher probability of using preventive services than all other statuses. This result agrees with previous research indicating that generally marriage acts positively for the promotion of good health-related behaviours [32], and the increase in utilisation rates of preventive health services [33], particularly for men [34].

Furthermore, people with higher incomes were slightly more likely to use preventive health services than people with lower incomes. Literature has either indicated a positive relationship between higher income / social class and utilisation rates of preventive services [24, 35], or no relationship at all [27]. More research is necessary into the role of income and socioeconomic status in the uptake of preventive health checks.

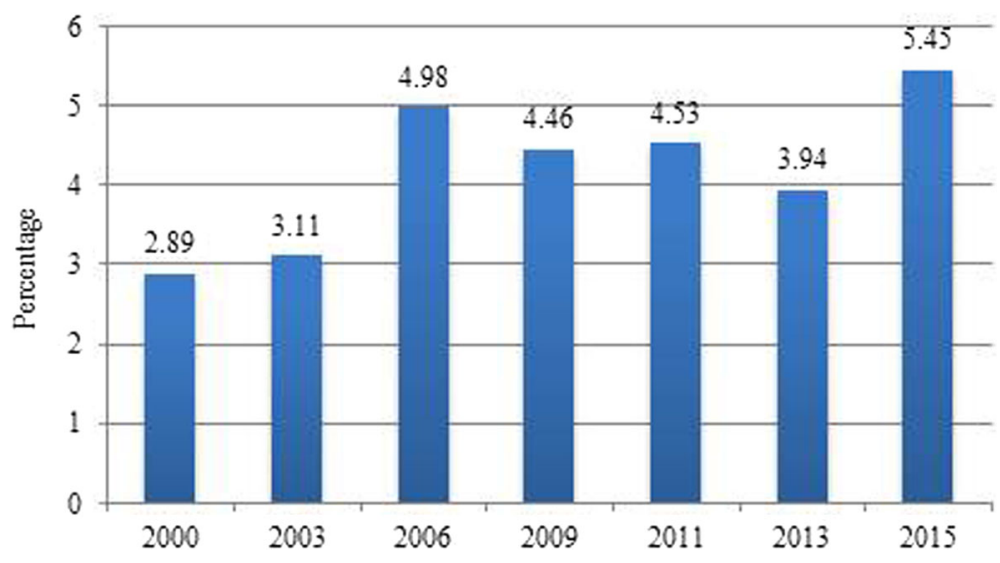

Fig. 1 Chilean adults (\%) using preventive health services, 2000-2015 
Table 2 Results of logistic regressions using preventive services as dependent variable

\begin{tabular}{|c|c|c|c|}
\hline \multirow[t]{2}{*}{ Variables } & (1) & (2) & (3) \\
\hline & OR $(95 \% \mathrm{Cl})$ & OR $(95 \% \mathrm{Cl})$ & OR $(95 \% \mathrm{Cl})$ \\
\hline \multicolumn{4}{|l|}{ Sex (male as reference) } \\
\hline Female & $\begin{array}{l}1.28^{* * *} \\
(1.23-1.33)\end{array}$ & $\begin{array}{l}1.17^{* * *} \\
(1.12-1.23)\end{array}$ & $\begin{array}{l}1.16^{* * *} \\
(1.11-1.21)\end{array}$ \\
\hline \multicolumn{4}{|c|}{ Geographical location (urban as reference) } \\
\hline Rural & $\begin{array}{l}.92^{* * *} \\
(.87-.96)\end{array}$ & $\begin{array}{l}.90^{* * *} \\
(.86-.95)\end{array}$ & $\begin{array}{l}.90^{* * *} \\
(.86-.95)\end{array}$ \\
\hline Age (years) & $\begin{array}{l}1.07^{* * *} \\
(1.07-1.08)\end{array}$ & $\begin{array}{l}1.07^{* * *} \\
(1.06-1.07)\end{array}$ & $\begin{array}{l}1.07^{* * *} \\
(1.06-1.07)\end{array}$ \\
\hline \multicolumn{4}{|l|}{ Civil status (married as reference) } \\
\hline Living with or in a relationship & $\begin{array}{l}.87^{* * *} \\
(.81-.93)\end{array}$ & $\begin{array}{l}.89^{* *} \\
(.82-.95)\end{array}$ & $\begin{array}{l}.88^{* *} \\
(.82-.95)\end{array}$ \\
\hline Separated, divorced, annulled & $\begin{array}{l}.96 \\
(.89-1.04)\end{array}$ & $\begin{array}{l}1.02 \\
(.95-1.10)\end{array}$ & $\begin{array}{l}1.03 \\
(.95-1.11)\end{array}$ \\
\hline Widowed & $\begin{array}{l}.94^{*} \\
(.89-.99)\end{array}$ & $\begin{array}{l}.94^{*} \\
(.88-.99)\end{array}$ & $\begin{array}{l}.94^{*} \\
(.89-.99)\end{array}$ \\
\hline Single & $\begin{array}{l}.85^{* * *} \\
(.80-.90)\end{array}$ & $\begin{array}{l}.84^{* * *} \\
(.79-.89)\end{array}$ & $\begin{array}{l}.85^{* * *} \\
(.80-.91)\end{array}$ \\
\hline \multicolumn{4}{|c|}{ Indigeneity (not indigenous as reference) } \\
\hline Indigenous & $\begin{array}{l}1.03 \\
(.96-1.10)\end{array}$ & $\begin{array}{l}1.03 \\
(.96-1.10)\end{array}$ & $\begin{array}{l}1.02 \\
(.95-1.10)\end{array}$ \\
\hline \multicolumn{4}{|l|}{ Nationality (Chilean as reference) } \\
\hline Foreigner & $\begin{array}{l}.90 \\
(.71-1.13)\end{array}$ & $\begin{array}{l}.91 \\
(.72-1.15)\end{array}$ & $\begin{array}{l}.97 \\
(.76-1.23)\end{array}$ \\
\hline Equalised income (log) & & $\begin{array}{l}1.11^{* * *} \\
(1.08-1.15)\end{array}$ & $\begin{array}{l}1.13^{* * *} \\
(1.09-1.17)\end{array}$ \\
\hline Education (years) & & $\begin{array}{l}.99^{* * *} \\
(.98-.99)\end{array}$ & $\begin{array}{l}.99^{* *} \\
(.98-.99)\end{array}$ \\
\hline \multicolumn{4}{|c|}{ Employment (employed as reference) } \\
\hline Unemployed & & $\begin{array}{l}1.04 \\
(.88-1.22)\end{array}$ & $\begin{array}{l}1.06 \\
(.90-1.26)\end{array}$ \\
\hline Inactive & & $\begin{array}{l}1.40^{* * * *} \\
(1.33-1.48)\end{array}$ & $\begin{array}{l}1.41^{* * *} \\
(1.33-1.48)\end{array}$ \\
\hline \multicolumn{4}{|c|}{ Health self-assessment (bad as reference) } \\
\hline Neither good nor bad & & & $\begin{array}{l}1.18^{* * *} \\
(1.11-1.26)\end{array}$ \\
\hline Good & & & $\begin{array}{l}1.14^{* *} \\
(1.06-1.22)\end{array}$ \\
\hline \multicolumn{4}{|c|}{ Health provider (FONASA as reference) } \\
\hline Armed forces & & & $\begin{array}{l}.92 \\
(.81-1.05)\end{array}$ \\
\hline ISAPRE & & & $\begin{array}{l}.89^{* *} \\
(.81-.96)\end{array}$ \\
\hline Out-of-pocket & & & $\begin{array}{l}.42^{* * *} \\
(.33-.51)\end{array}$ \\
\hline \multicolumn{4}{|l|}{ Disability (no as reference) } \\
\hline Yes & & & $\begin{array}{l}1.04 \\
.99-1.10)\end{array}$ \\
\hline LR chi2 & $17,770.10$ & $17,923.71$ & $17,576.60$ \\
\hline Prob > chi2 & 0.0000 & 0.0000 & 0.0000 \\
\hline McFadden R2 & 0.197 & 0.200 & 0.200 \\
\hline
\end{tabular}


Table 2 Results of logistic regressions using preventive services as dependent variable (Continued)

\begin{tabular}{|c|c|c|c|}
\hline \multirow[t]{2}{*}{ Variables } & (1) & (2) & (3) \\
\hline & OR $(95 \% \mathrm{Cl})$ & OR (95\% Cl) & OR $(95 \% \mathrm{Cl})$ \\
\hline Deviance & $72,250.482$ & $71,762.361$ & $70,243.872$ \\
\hline AIC & $72,270.482$ & $71,790.361$ & $70,283.872$ \\
\hline $\mathrm{BIC}$ & $72,373.157$ & $71,934.053$ & $70,488.597$ \\
\hline
\end{tabular}

${ }^{*} p<0.05,{ }^{* *} p<0.01,{ }^{* * *} p<0.001$

People with an average or good self-assessed health score were more likely to undertake preventive health checks than people who graded their health as 'bad'. Previous studies on the relationship between self-evaluated health and preventive services have not provided definite results. For example, in a study by Labeit, Peinemann, and Baker, while poor self-rated health status increased the utilisation of blood pressure checks by about $12.6 \%$, there was no significant influence of poor health status on utilisation rates with regards to breast and cervical cancer screening [27]. Another study showed that individuals that were in poorer health were more likely to get flu shots and cholesterol checks, but less likely to have mammograms, pap smears, breast examinations, and prostate checks [36].

Being unemployed (i.e. people who are not employed but are in search of a job) did not show a statistically significant relationship with preventive services. Being inactive (i.e. people who are neither employed, nor are looking for a job, either due to age or serious disability), however, did: inactive people were 1.4 times more likely to use preventive services than employed people. This might be on account of more available free time to perform such checks. Being employed has been found to be associated with lower uptake of breast screening in the UK [27].

Finally, education did not have an impact on the utilisation rates of preventive services; while statistically significant, the coefficient was very close to 1 . Taking into account that higher education is generally linked to better health outcomes and better health literacy [37], it would be reasonable to assume that people with higher education are more likely to use preventive health services. However, research on this relationship has not provided a definite answer: some studies have found a positive relationship between higher education and utilisation of preventive services [38, 39], ,others have not found a statistically significant relationship [6], while others have found a statistically significant relationship only for certain types of preventive services, such as dental screening [27].

Our findings also show that individuals affiliated with FONASA are more likely to use preventive health services than individuals affiliated with an ISAPRE. As seen previously, in order to access these services for free, FONASA affiliates have to go to the health facility where they are registered, while affiliates with an ISAPRE have to go to the providers defined by their ISAPRE; otherwise they have to pay [16]. However, ISAPRE affiliates, who usually enjoy a better socioeconomic status, often prefer going to their own doctors and health facilities, and therefore, take on an additional cost for their decision, thus paying for convenience. For example, in 2015 only $27 \%$ of the preventive services undertaken by ISAPRE affiliates were performed completely free of charge; the vast majority paid a co-payment of a total of 3.8 billion Chilean pesos (about US\$ 5.8 million, current prices). The high amount of co-payments can be also due to the lack of information from the ISAPREs regarding the free preventive services to which their affiliates

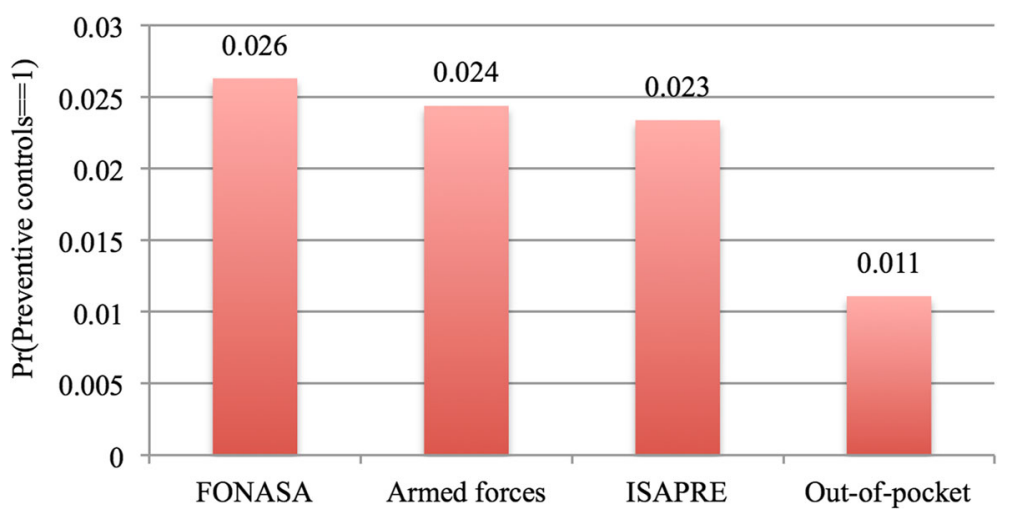

Fig. 2 Estimated probabilities for utilisation of preventive health services with health provider as predictor variable 
are entitled [40]. Employment status might be another possible reason why people affiliated with an ISAPRE do not use preventive services, since this may mean losing a day of work.

The general low percentage of Chilean adults undertaking preventive health services - estimated at around 13$14 \%$ of the total population - is a matter of concern. In the US, for example, about $20 \%$ of people use preventive health services every year, with utilisation rates depending on region and insurance type [41]. Another study showed that $50 \%$ of Austrian adults have at least one comprehensive preventive health check-up a year [24].

In the particular case of Chile, it is important that people affiliated with an ISAPRE are able to use preventive services at a clinic or hospital of their choice when they sign up with a particular ISAPRE. At the moment, only about $7 \%$ of people using preventive health services are affiliated with an ISAPRE; one of the reasons might be that they can go only to the providers defined by their ISAPRE in order to access these services free of charge.

\section{Strengths and limitations}

Due to the cross-sectional nature of the data, we cannot make any causal inferences as to the reasons for the observed differences in the utilisation rates of preventive health services. Another limitation is that it was not possible to investigate barriers to utilisation rates of preventive services going further back in time, due to the fact that the wording of the particular question on preventive services was different pre-2011. Also, it would have been interesting if other variables could be added - such as weight or lifestyle habits - that could have had an impact on utilisation rates of preventive health services; such information, however, is not available in the CASEN survey.

This study has, nevertheless, offered interesting insights on preventive health services for adults. The literature on this topic is quite limited, with most studies investigating relatively small population samples, and focusing on particular subpopulations [7], or on specific preventive services [5]. The current study used data from over 200,000 Chilean adults - a sample that was representative of the population - taken from a valid and reliable socioeconomic survey, in an effort to investigate demographic, socioeconomic, and health-related factors influencing the utilisation rates of preventive health services.

Another significant aspect of the study is that it looked into the difference in utilisation rates, depending on the affiliation with a public or private health provider; this is particular important, especially in countries - such as Chile - that are characterised by high income inequality (Gini index of 0.485 in 2015, according to the Ministry of Social Development) [42], as well as high inequality in access and utilisation of health care services $[8,9]$.

\section{Implications and recommendations}

It is necessary to address the barriers that prevent a high percentage of the population from using preventive health services. It is paramount to promote a more effective information campaign on the availability and necessity of undertaking preventive health services, especially at parts of the population who report low use. Also, the availability of primary care physicians is important, since studies have shown that this can increase people's probability of having a physician, which in turn increases preventive health care service utilisation [43]. This should be coupled with a more active physician promotion of preventive health services [44], and a better health care provider - patient communication [45], factors that have been shown to lead to an increase in the uptake of preventive health exams. It is also important to address the wider, socio-political issues related to the uptake of preventive health services, such as affordability, accessibility, and availability of services.

\section{Conclusions}

This study investigated the factors associated with the utilisation rates of preventive health care services for Chilean adults. The results showed that women, older people, married people, those with higher incomes, inactive people, and people with an average or good self-assessed health had higher odds of undergoing preventive checks. On the other hand, people living in rural areas, single people, and people that were affiliated with the private health care provider or paid out-of-pocket had fewer odds of doing so.

Not using preventive services can have detrimental effects on individuals and population health - particularly in countries such as Chile that are characterised by high income inequality and stratification of health care services - since it can a) lead to premature death, disability, and ill health; b) result in more days of work lost and subsequent productivity losses, as well as lost taxes and increased welfare payments; and c) lead to increased direct costs to health care systems [46]. With population ageing and an increase in age-related and lifestyle-related diseases, it is important that a larger percentage of the population has access to preventive health services.

\section{Abbreviations}

AUGE-GES: Acceso Universal a Garantías Explícitas en Salud- Garantías Explícitas en Salud; CASEN: Encuesta Nacional de Caracterización

Socioeconómica; FONASA: Fondo Nacional de Salud; ISAPRE: Instituciones de Salud Previsional; PME: Preventive Medical Examination

Availability of data and materials

The datasets analysed in the current study are available in the Ministry of Social Development of Chile repository http://

observatorio.ministeriodesarrollosocial.gob.cl/casen/casen_2015.php. 


\section{Authors' contributions}

ESR and DS jointly conceived the final research question and aims and objectives, reviewed the literature, produced the analysis plan and carried out the analysis, and drafted the manuscript. All authors read and approved the final manuscript.

\section{Ethics approval and consent to participate}

Not applicable.

\section{Consent for publication}

Not applicable.

\section{Competing interests}

The authors declare that they have no competing interests.

\section{Publisher's Note}

Springer Nature remains neutral with regard to jurisdictional claims in published maps and institutional affiliations.

\section{Author details}

'Department of Economics, University of Chile, Diagonal Paraguay 257, Office 1506, 8330015 Santiago, Chile. ${ }^{2}$ Cardiff University, School of Healthcare Sciences, Eastgate House, Newport Road 35-43, Cardiff CF24 OAB, UK.

\section{Received: 27 February 2018 Accepted: 26 June 2018}

\section{Published online: 06 July 2018}

\section{References}

1. Cáceres CF, Mendoza W. Changing care and prevention needs for global public health: In pursuit of a comprehensive perspective. Glob Public Health. 2011;7(sup1):s29-45.

2. Nakanishi N, Tatara K, Fujiwara H. Do preventive health services reduce eventual demand for medical care? Soc Sci Med. 1996;43(6):999-1005.

3. INE. Estadísticas demográficas y vitales. Instituto Nacional de Estadísticas; 2017. Retrieved from: http://www.ine.cl/estadisticas/demograficas-y-vitales.

4. Baechler RR, Barra MR, Soto A. Índice de medicina preventiva. Una medida integradora de la cobertura de los programas preventivos. Rev Med Chil. 2007;135(6):777-82.

5. Sakellariou D, Rotarou ES. Utilisation of cancer screening services by disabled women in Chile. PLoS One. 2017;12(5):e0176270.

6. Schülein S, Taylor KJ, Schriefer D, Blettner M, Kluga SJ. Participation in preventive health check-ups among 19,351 women in Germany. Prev Med Rep. 2017:6:23-6.

7. Yen SM, Kung PT, Chiu LT, Tsai WC. Related factors and use of free preventive health services among adults with intellectual disabilities in Taiwan. BMC Health Serv Res. 2014;14:248.

8. Labra M. La reinvención neoliberal de la inequidad en Chile. El caso de la salud. Cadernos de Saúde Pública. 2002;18(4):1041-52.

9. Núñez A, Chi C. Equity in health care utilisation in Chile. Int J Equity Health. 2013;12:58.

10. Rotarou ES, Sakellariou D. Neoliberal reforms in health systems and the construction of long-lasting inequalities in health care: a case study from Chile. Health Policy. 2017;121(5):495-503.

11. FONASA. Boletín estadístico 2015-2016; 2017. Retrieved from: https://www. fonasa.cl/sites/fonasa/institucional/archivos.

12. Unger JP, De Paepe P, Solimano GC, Arteaga OH. Chile's neoliberal health reform: an assessment and a critique. PLoS Med. 2008;5(4):e79.

13. Superintendencia de Salud. Cartera de beneficiarios de ISAPREs año 2015; 2016. Retrieved from: http://www.supersalud.gob.cl/documentacion/666/ w3-propertyvalue-3741.html.

14. Leiva L. Mujeres pagan hasta $66 \%$ más que los hombres en sus planes de salud de isapres. La Tercera, Nacional, 23-12-2016; 2016. Retrieved from: http://www.latercera.com/noticia/mujeres-pagan-66-mas-los-hombresplanes-salud-isapres/.

15. Trincado P. Visión global de la medicina preventiva en Chile. Revista Médica Clínica Las Condes. 2010;21(5):669-73.

16. Ministry of Health. Examen medicina preventiva; 2015. Retrieved from: http://www.minsal.cl/examen-medicina-preventiva/.

17. Ministry of Health. Guía clínica: Examen de medicina preventiva. Santiago: Ministry of Health; 2008.
18. DEIS. REM 2015: Datos preliminaries; 2016. Retrieved from: http://www.deis. cl/rem-2015/.

19. Clínicas de Chile. Chequeos médicos preventivos en clínicas privadas aumentan sobre 30\% en últimos cinco años; 2017. Retrieved from: http:// www.clinicasdechile.cl/noticias/chequeos-medicos-preventivos/.

20. Universidad de Chile. Encuesta CASEN 2015: Manual de trabajo de campo; 2014. Santiago: Centro de Microdatos, Facultad de Economía y Negocios, Universidad de Chile.

21. Ministry of Social Development. Observatorio social: Encuesta CASEN; 2016. Retrieved from: http://observatorio.ministeriodesarrollosocial.gob.cl/casen/ casen_2015.php.

22. Herrera, R., Larrañaga, O., and Telias, A. La Ficha de protección social. Working document 2010:3. PNUD-Chile.

23. Vaida V, Partha G, Karmakar M. Gender differences in utilisation of preventive care services in the United States. J Womens Health. 2011; 21(2):140-5

24. Brunner-Ziegler S, Rieder A, Stein KV, Koppensteiner R, Hoffmann K, Dorner TE. Predictors of participation in preventive health examinations in Austria. BMC Public Health. 2013:13:1138.

25. Viera AJ, Thorpe JM, Garrett JM. Effects of sex, age, and visits on receipt of preventive healthcare services: a secondary analysis of national data. BMC Health Serv Res. 2006;6:15

26. Qin $L, X u H$. . A cross-sectional study of the effect of health literacy on diabetes prevention and control among elderly individuals with prediabetes in rural China. BMJ Open. 2016;6:e011077.

27. Labeit A, Peinemann F, Baker R. Utilisation of preventative health check-ups in the UK: findings from individual-level repeated cross-sectional data from 1992 to 2008. BMJ Open. 2013:3:e003387.

28. Teo $\mathrm{CH}, \mathrm{Ng} \mathrm{CJ}$, Booth $\mathrm{A}$, White A. Barriers and facilitators to health screening in men: a systematic review. Soc Sci Med. 2016;165:168-76.

29. CDC. Cancer screening - United States, 2010. Morb Mortal Wkly Rep. 2012; 61(3):41-5.

30. NHS. NHS cervical screening programme: Annual review 2011; 2011. Retrieved from: http://webarchive.nationalarchives.gov.uk/20150505170644/ http://www.cancerscreening.nhs.uk/cervical/publications/cervical-annualreview-2011.pdf

31. Moser K, Patnick J, Beral V. Inequalities in reported use of breast and cervical screening in great Britain: analysis of cross sectional survey data. BMJ. 2009:338:b2025.

32. Steinberg BS, Weinick RM. Health-related behaviours and the benefits of marriage for elderly persons. Gerontologist. 1998;38(5):618-27.

33. Van Jaarsveld $\mathrm{CH}$, Miles $\mathrm{A}$, Edwards $\mathrm{R}$, Wardle J. Marriage and cancer prevention: does marital status and inviting both spouses together influence colorectal cancer screening participation? J Med Screen. 2006; 13(4):172-6.

34. Blumberg SJ, Vahratian A, Blumberg JH. Marriage, cohabitation, and men's use of preventive health care services. NCHS data brief, no. 154. Washington DC: US Department of Health and Human Services, centers for disease control and Prevention; 2006

35. Garrido-Cumbrera M, Borrell C, Palencia L, Espelt A, Rodríguez-Sanz M, Pasarín MI, Kunst A. Social class inequalities in the utilization of health care and preventive services in Spain, a country with a national health system. Int JHealth Serv. 2010:40(3):525-42.

36. Wu S. Sickness and preventive medical behaviour. J Health Econ. 2003; 22(4):675-89.

37. Hahn RA, Truman BI. Education improves public health and promotes health equity. Int J Health Serv. 2015;45(4):657-78.

38. Fernandez DM, Larson JL, Zikmund-Fisher BJ. Associations between health literacy and preventive health behaviours among older adults: findings from the health and retirement study. BMC Public Health. 2016;16:596.

39. Lange $F$. The role of education in complex health decisions: evidence from cancer screening. JHealth Econ. 2011:30(1):43-54.

40. Leiva L. Sólo el 27\% de los exámenes preventivos en Isapres se practicaron por el sistema gratuito. La Tercera, Nacional, 14-02-2016; 2016. Retrieved from: http://www.latercera.com/noticia/solo-el-27-de-los-examenespreventivos-en-isapres-se-practicaron-por-el-sistema-gratuito/.

41. Mehrotra A, Zaslavsky AM, Ayanian JZ. Preventive health examinations and preventive gynaecological examinations in the United States. Arch Intern Med. 2007;167(17):1876-83.

42. Ministry of Social Development. CASEN 2015: Resultados y distribución de ingresos; 2016. Retrieved from: http://observatorio.ministeriodesarrollosocial. 
gob.cl/casen-multidimensional/casen/docs/CASEN_2015_Ingresos_de_los_ hogares.pdf.

43. Continelli T, McGinnis S, Holmes T. The effect of local primary care physician supply on the utilization of preventive health services in the United States. Health Place. 2010;16(5):942-51.

44. Wardle J, Robb K, Vernon S, Waller J. Screening for prevention and early diagnosis of cancer. Am Psychol. 2015;70(2):119-33.

45. Wallace LS, DeVoe JE, Bennett IM, Roskos SE, Fryer GE Jr. Perceptions of healthcare providers' communication skills: do they differ between urban and non-urban residents? Health Place. 2008;14(4):653-60.

46. Frontier Economics-Marmot Review. Estimating the costs of health inequalities - a report prepared for the marmot review. London: Frontier Economics; 2010.

- fast, convenient online submission

- thorough peer review by experienced researchers in your field

- rapid publication on acceptance

- support for research data, including large and complex data types

- gold Open Access which fosters wider collaboration and increased citations

- maximum visibility for your research: over $100 \mathrm{M}$ website views per year 